\title{
Briefing: Smart cities: dividing the UK
}

Kimberley Faithfull-Wright BSC (Hons)

Smart Places Lead, Costain, Maidenhead, UK

(kimberley.faithfull-wright@costain.com)

This briefing aims to highlight the applicability of smart city visions, principles and technology solutions to more rural locations within the UK to promote the benefits of 'smart region' strategies. It highlights the difference between living standards in urban and rural settings and why it is important for both environments to learn from each other in order to both benefit and bring down the divide between them. This briefing also aims to understand the impact that smart solutions can have on start-ups and small- to medium-sized enterprises, with the emergence of new rural challenges to drive additional innovation and local enterprise.

\section{Introduction}

Smart cities have been a focus area for many years to allow better liveability for the increasing majority of those who populate the densest urban areas. However, this risks creating further silos and a cultural divide across the UK by driving focus towards improvement of urban areas and neglecting those who live more rurally. Rural areas, like cities, have their own unique challenges regarding transportation, energy, public services and infrastructure. Some solutions being developed in urban areas are primed to solve these challenges, and others pose an innovative spark that could excite the numerous new small- to medium-sized enterprises (SMEs) entering the market, who themselves attract innovation funding. Is the smart city concept hindering development in neighbouring rural areas? Many city concepts focus on green space, better air quality and creating more aesthetic places to live. So is the UK missing an opportunity to open up doors for innovation in areas where these drivers have always been a priority?

A smart city is a place which has been designed for its people; whether this be the creation of better transport networks, smart infrastructure, improved healthcare facilities or more green spaces, the place itself is designed for and by its citizens. The concept therefore becomes far more broadly applicable than its city focus, enabling these principles to be developed and implemented in any place with citizen needs. It is therefore important that smart principles are adopted not just by existing large cities, but also by other places where the UK will see a population increase, making these principles just as applicable to towns, rural and semi-rural locations.

Looking at smart technology, a similar approach can be taken to that of the smart city concept. Smart technology does not just have smart city applications, but is rather an ambiguous term that can refer to any innovative technology used in sectors such as retail, energy, healthcare, transport and telecommunications. Whether applicable to a smart city or not, smart technology tends to be badged alongside innovative smart city initiatives. These solutions can therefore be developed for a range of outcomes to suit this trend, opposed to a one-size-fits-all solution (Hosseini et al., 2018) that expects the same requirements in all locations, creating wider commercialisation opportunities.

\section{Smart city visions, principles and frameworks}

Over half the world's population already live in cities, and this is expected to rise to around $70 \%$ by 2050 . However, this does not always mean that existing cities are becoming bigger; it can also mean that new cities are forming due to population migration, creating new urban centres in previously more rural areas.

During the first two decades of the twenty-first century, there has been a technological revolution with a strong drive towards personalisation. There is now a more comprehensive understanding of how air, land and sea pollution has a negative impact on citizens' quality of life and focusing of a drive towards smart, sustainable solutions provided by city services. The outdated infrastructure and systems in a world of fast-paced technological changes are creating pressure on strained urban systems, creating challenges regarding network capacity, resource availability, infrastructure capacity and applicability and inequality. Engineering is now being used to transform cities and address the complexity of urban services and promote sustainability and liveability within cities.

Smart cities are one such concept that aims to address these challenges, but it can also cause more issues if not carried out holistically. Unless cities have a clear vision of high-level principles and the tools that they need to address new challenges of the changing societal requirements in a dynamic and effective way, the UK will struggle to enable a process of societally driven change (Ortegon and Tyler, 2018). These principles are the roots which form the basis of a structure to allow decisions to be made and prioritised through assessing projects, plans and actions which form part of a shared goal.

The PAS 180 series of documents (BSI, 2014a, 2014b, 2014c, 2014d) provide a set of terminology, frameworks and methodologies that can be used by any decision-making authority to identify and roadmap how they can become smarter. The documents outline how guiding principles should be visionary, citizen centric, digital and open and collaborative in order to move from a silo-function mentality to one of interrelated functional systems and ecological systems delivering citizen-centric service management. By 
understanding how these functions interrelate with and impact each other, funding and service delivery can be better allocated and streamlined. For example, by understanding the impact of vehicle emissions on citizens' health, healthcare funding could be apportioned to this and used to provide alternative fuelling infrastructure for low-emission vehicles. Although these documents are focused on a smart cities, the principles and guidance within them can be easily adopted by any place where there are decision makers, citizens and a need to resolve current and future challenges in a smart way.

In integrating smart infrastructure, Norway demonstrates the success that can be achieved through collaborative approaches and an aligned, countrywide vision. When deciding to integrate 400 charge points into Oslo in 2008 (C40 Cities, 2014) to promote electric vehicle (EV) uptake and tackle reduction of emissions, they understood that they would not see the required results by integrating new infrastructure in the city alone. By working with the EV Owners Association, accepting public proposals and listening to their businesses, they integrated infrastructure and incentives to facilitate EV adoption across the country (CPI, 2016). They now have the highest number of EVs per capita and have a new car sales market share for EVs of almost $50 \%$. They have also announced their plans to integrate further smart infrastructure in the country to enhance mobility, by installing submerged, floating bridges across fjords which will reduce travel times, ensure that rural communities stay connected to services and retain the nation's natural beauty.

\section{Urban-rural disparity}

The urban-rural divide describes the difference in living standards (both social and economic) between those who live in urban and rural locations and is prevalent in countries across the globe. With the advent of smart cities a decade ago and its increasing popularity, this divide has become all the more obvious. There are several factors key to the difference in living standards, and how these are perceived, that steer investment decisions and the public's understanding. There are pockets of extreme poverty and affluence in both urban and rural communities within the UK, enhanced by mobility issues in spatial segregation and access between rural and urban places. The divide is well known but intricately complex, and this paper will explore this only at a high level with regard to smart technologies that provide benefits to some of the challenges faced.

\subsection{Population}

Despite the focus on cities and prediction of increased population, the Office for National Statistics stated earlier this year that in 2016, 17\% of the population of England lived in predominantly rural areas (population under 30000 ), which, as can be seen in Figure 1, makes up $89 \%$ of England's land mass. Rural areas and their 9.4 million residents are not a small part of the country. However, smart city initiatives are pinned on the concept that more people will be moving to cities in the next few decades, focusing on improving lives there.
But how true is this prediction really? Between 2001 and 2015, the population in predominantly rural areas of England increased by $9 \cdot 5 \%$, compared to $11.6 \%$ in predominantly urban areas (ONS, 2018). So, if the rural population is increasing almost as much as the urban population, will the 2050 predictions be seen to come true in the ways and locations that are expected? More interestingly, since 2008/2009, there has been a steady increase in the rate of net migration to these rural areas, backing up the potential for formation of new urban centres appearing in the coming decades. In 2015/2016, predominantly rural areas saw a net population migration of 70500 people inwards (those moving to rural locations), whereas urban areas saw a net migration outwards (out of urban locations) of 105 100, with the majority of this being from London. This contrasts with the common belief that people are flocking to the cities and instead seems to back up quite the opposite. This may be a shift towards the generation of new towns and cities as people look for a better life elsewhere. If this is the case, the UK may end up with a landscape of more smaller cities, which makes upgrades to the country as a whole a more future-proofed approach.

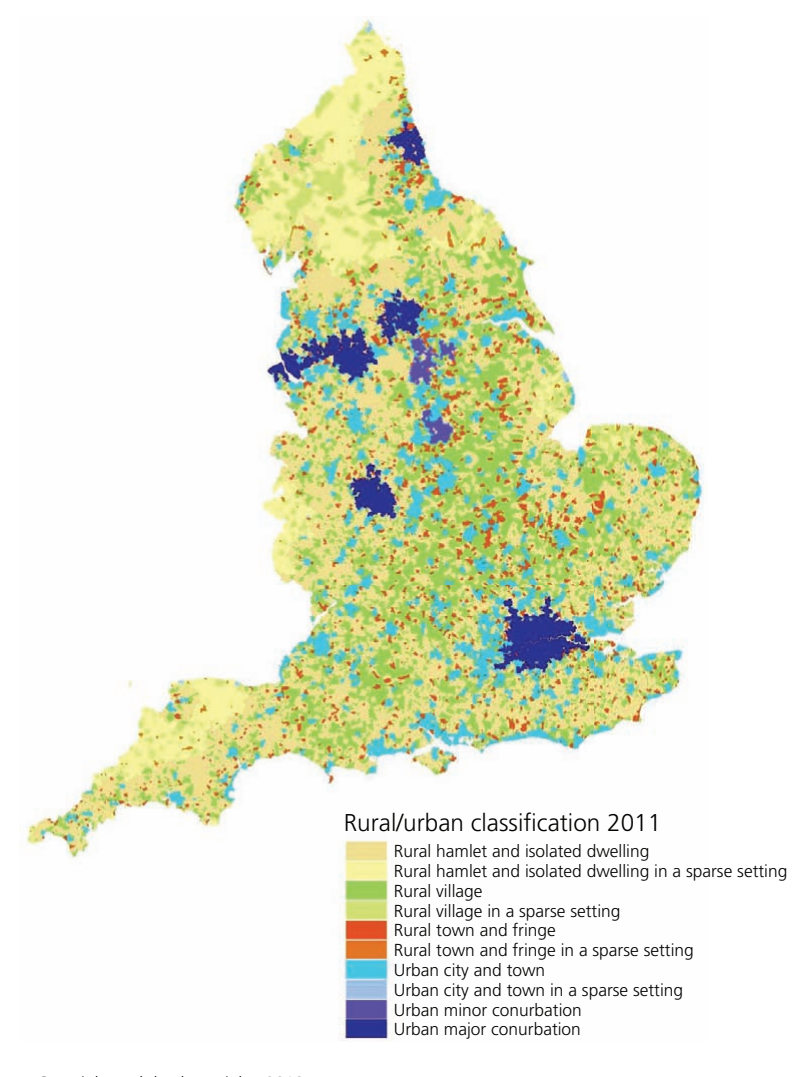

C Crown Copyright and database rights 2018 Ordnance Survey Licence No. 100022861

Figure 1. Diagram of 2011 rural-urban classification for census output areas in England. (C) Crown copyright 2018 Ordnance Survey. Media 053/18 
Table 1. Rural-urban statistical comparison. Statistical digest of rural England, January 2018 edition. (C) Crown copyright 2018

\begin{tabular}{|lcc|}
\hline & Rural & Urban \\
\hline Employment rate & $78 \%$ & $74 \%$ \\
Unemployment rate & $3 \cdot 4 \%$ & $5 \cdot 1 \%$ \\
GVA & $16 \cdot 4 \%$ & $44.5 \%$ \\
& (other rural 11.9\%) & (London $27 \cdot 3 \%)$ \\
Homeworking & $22 \%$ & $13 \%$ \\
Registered business & 49 per 10000 & 53 per 10000 \\
$\quad$ start-ups & $24 \%$ & $76 \%$ \\
Registered SMEs & $47 \%$ of businesses & $49 \%$ of businesses \\
Innovation activities &
\end{tabular}

\subsection{Economy}

One of the more obvious differences between rural and urban living is in economy. For a long time, people have assumed that those living in rural areas are better off and that rural areas of the UK contribute less to the economy.

Table 1 shows that, while employment rates are better in rural locations, they do contribute less to UK's gross value added (GVA), mainly due to fewer businesses being registered in rural locations (537 000 registered in 2015/2016) and many employees living rurally commuting or working remotely for urban-based businesses. When these statistics are related to smart cities, they highlight where the concepts and solutions can really add value. With a larger number of homeworkers and commuters in rural areas, technology can enable the productivity increase needed to enable an increase in rural GVA. Better Internet connection and networks to other services (e.g. transport connections) can increase the way that rural workers and new start-ups operate and succeed. Almost a quarter of UK's registered SMEs are rural, but are they receiving the support and opportunities that they need to address their local challenges? Or are they hindered by the funding and development focus in the city?

\subsection{Living standards}

The traditional notion that those living in the countryside are better off is, in a way, very true. The weekly disposable income is $£ 192$ more in rural households than in urban ones, so rural residents are on average financially better off. However, expenditure in a rural household is on average $£ 164$ more than an urban household due to more expensive housing and utility/transport costs. Rural areas also have reduced poverty, with only $16 \%$ of residents in relatively low-income households compared to $23 \%$ in urban areas (after housing costs). For children living in poverty, this increases to $22 \%$ in rural areas and $31 \%$ in urban areas, further enforcing the notion that a better standard of living can be found rurally. Although rural areas tend to be richer, they also have greater poverty of access and inaccessibility compared with urban areas.

However, financials are only one aspect of living standards. In $2015 / 2016$, people living in rural areas travelled almost $50 \%$ further each year, with $88 \%$ of this being made by car. Bus availability in rural areas (where a bus is within a 13 min walk and runs at least every hour) is between 49 and $86 \%$, compared to a consistent $97 \%$ in urban areas (2012), demonstrating the lack of transportation connections in rural areas. When this is combined with service availability, it can be seen why this may cause mobility issues. The average minimum time for rural people to reach a hospital by public transport was $1 \mathrm{~h}$, double that of urban areas. Half of rural residents have a large employer within a 45 min commute, compared to $90 \%$ in urban areas, contributing to rural unemployment. Rural schoolchildren generally travel more than double the distance to get to school due to lack of school services, reducing the number of children who walk and cycle to school compared to urban areas.

It is not just services which cause an issue in rural areas. Many of the buildings and houses are less energy efficient than urban homes, meaning that fuel poverty is proportionally more prevalent in rural areas. There are also different fuel mixes due to rural areas being off the main energy grid, which causes higher fuel costs as well as additional fuel required for basic transport. The fuel poverty gap for rural villages, hamlets and dwellings in 2014 was $£ 838$, significantly more on average than urban homes.

Most people are aware of the environmental requirements and targets on the UK to reduce carbon dioxide emissions and increase air quality. What is not so topical is that the urban areas being targeted are not the only place where this is a problem. In urban environments, the carbon dioxide footprint ("carbon footprint') per person is on average half of the carbon footprint of someone living rurally. Both of the travel options service availability and energy consumption play a vital role in the reason for this high carbon footprint.

\section{Emergence of new rural challenges}

These statistics and difference identify several areas where rural places can benefit from the funding, innovation and solutions being developed to enhance living standards in cities.

Innovative solutions and smart infrastructure in energy efficiency, sustainability, future mobility and connectivity are key areas that can help solve challenges faced by rural communities, learning from urban environments to increase living standards and achieve UK targets. When tackling environmental challenges, the focus for rural locations should be on the personal footprint of its inhabitants, driving SMEs and larger organisations to create solutions to these key challenges as well as to solve those within cities.

One hindrance to local solution development could be connectivity. Table 2 demonstrates that there are still a large proportion of rural areas that either has no Internet connectivity or has poor connectivity (Ofcom, 2017), and it is well recognised that many rural areas also lack good mobile connectivity. This can create issues with solution adoption, start-up of businesses, homeworking and access to online services such as e-learning, e-healthcare, shopping and council services. Connectivity in the twenty-first century is a fundamental foundation for adoption and 
Table 2. Connectivity in urban and rural areas - England/Wales

$\begin{array}{lccc}\text { Measure } & \text { Urban } & \text { Rural town } & \begin{array}{c}\text { Rural } \\ \text { village }\end{array} \\ \text { Superfast available: \% } & 95 & 89 & 66 \\ \text { Receiving under 2 Mbps: \% } & 1 \cdot 6 & 2 \cdot 8 & 8 \cdot 1 \\ \text { Receiving under 10 Mbps: \% } & 22 & 22 & 47 \\ \text { Receiving over 30 Mbps: \% } & 52 & 41 & 31 \\ \text { Unable to receive 10 Mbps: \% } & 1 \cdot 3 & 2 \cdot 9 & 16 \cdot 9 \\ \text { Average speed Mbps: \% } & 48 \cdot 6 & 32 \cdot 2 & 25 \cdot 5\end{array}$

Mbps, megabits per second

\section{Case study - East Sussex, UK}

One success story for rural connectivity integration was in East Sussex, UK. In 2011, the Office of Communications estimated that only $3 \%$ of homes and businesses in East Sussex had access to superfast broadband (24+ Mbps). Private-sector business plans were estimated to extend coverage to only around $35 \%$ based on perceived uptake. This was due to several factors, but predominantly the rural topology's increasing infrastructure costs, perceived low uptake due to deprivation and the dispersed nature of the population across the country.

Of the 64 exchanges in East Sussex, only one exchange was enabled to deliver fibre with another 18 that managed to secure an upgrade funded by the private sector. This left 46 exchanges to be tackled through public-sector intervention. Subsequently, East Sussex committed to fund these upgrades to facilitate superfast broadband to extend to $99 \%$ of their region, including bridging gaps to business and industrial parks.

Uptake so far has far exceeded expectations and has allowed rural areas to be connected and citizens to access online services, facilitated economic growth and put the country on a connectivity par with larger cities.

Figure 2. Case study: the eSussex programme, increasing fibre connectivity in East Sussex (ESCC, 2019)

implementation of many smart solutions in the UK. Figure 2 demonstrates how this has been achieved in East Sussex, UK, which have a large rural demographic.

\section{Smart solutions for rural communities}

A range of smart solutions already exist that could benefit rural challenges. A key challenge for rural regions is the lack of fibre and $4 \mathrm{G}$ connectivity to enable these solutions; the hybrid connectivity mesh developed for urban environments can easily be transferred to a rural setting. This could be done through integration of Wi-Fi and sensor adaptors on existing street furniture, a commonality between the urban and rural environments. Enhancing connectivity not only enables other smart solutions, but also allows access to enhanced services for both residents and businesses. For residents in particular, it can allow access to online learning, job searches/advice and services such as e-healthcare, increasing living standards and bringing services closer to rural communities which need them most. Digital Salford is working on solutions in this area to close the connectivity gap and combat digital exclusion, which could be a barrier to the older or disabled rural population, maximising the benefits from smart solutions and creating equal living standards.

The Internet of things (IoT) is becoming more prevalent and valuable in urban data gathering, communication and decisionmaking; these benefits are also applicable to rural settings. IoT can be used for sensing and data collection in areas such as livestock management, river-level monitoring for flood prevention and traffic flow data collection to identify rural traffic trends.

To tackle the high carbon footprint and fuel poverty, renewable generation, energy storage and community microgrid solutions can be developed for rural communities that have restricted or no grid connection. This could allow for better EV uptake and lower fuel prices. Installation of electric heat pumps which is currently being trialled in Bridgend, Wales, as part of the Freedom project could provide an alternative for those disconnected from the main gas grid and can also form part of a microgrid system or heat network. These solutions are already being developed and trialled and can easily be adapted to solve rural challenges and increase living standards for citizens.

\section{Conclusion}

Some of the solutions being developed for urban areas are already part of smart city initiatives, mainly developed by SMEs in cities. This is by no means a one-way transaction. Rural communities have many characteristics and developed behaviours that cities are trying to replicate. Green space, community engagement and pleasant, walkable areas are some of these traits that rural communities and businesses can help urban environments to develop.

Further research and funding in needed to promote development and implementation of smart solutions in rural regions. Although there are several rural-focused research projects across Europe, this is still insignificant in comparison to the amount of urban smart research projects. EU Action for Smart Villages (Hogan et al., 2018) is one such research project which encompasses a range of smart, inclusive rural-focused projects to drive rural innovation but acknowledges that it is only one step in many which need to be taken to future-proof rural communities.

With a variety of business start-ups and innovation activities in rural areas, combined with them having almost a quarter of the UK's SMEs, rural areas should be able to create their own innovation hubs and solutions to rural-specific challenges. What they lack is the support and funding needed to tackle these challenges and implement solutions. It is a common opinion that the major challenges are in cities, and they will affect the most people in the future, so the majority of funding and support has been focused there. However, there are now multiple companies creating duplicate solutions to the same urban challenges, creating a competitive environment for all organisations in this space. If some focus is diverted onto rural challenges, it creates opportunities for SMEs to develop new solutions and open up opportunities for commercialisation. With new rural and urban 
partnerships, the UK could create a new, exportable market for businesses, creating new economic growth while tackling the rural urban divide and ensuring that the UK becomes a smart, connected and inclusive country, instead of a scattering of intercompeting smart cities.

\section{REFERENCES}

BSI (2014a) PAS 180:2014: Smart cities. Vocabulary. BSI, London, UK

BSI (2014b) PAS 181:2014: Smart city framework. Guide to establishing strategies for smart cities and communities. BSI, London, UK.

BSI (2014c) PAS 182:2014: Smart city concept model.

Guide to establishing a model for data interoperability.

BSI, London, UK.

BSI (2014d) PD 8101:2014: Smart cities. Guide to the role of the planning and development process. BSI, London, UK.

C40 Cities (2014) Case Study: the Electric Vehicle Capital of the World. C40 Cities, New York, NY, USA. See https://www.c40.org/case studies/the-electric-vehicle-capital-of-the-world (accessed 14/03/2019)

CPI (Centre for Public Impact) (2016) Case Study: the Rise of Electric Vehicles in Norway. CPI, London, UK. See https://www. centreforpublicimpact.org/case-study/electric-cars-norway/ (accessed 14/03/2019).

ESCC (East Sussex County Council) (2019) https://esussex.org/Home/About (accessed 14/03/2019)

Hogan P, Crețu C and Bulc V (2018) EU Action for Smart Villages. European Commission, Brussels, Belgium. See https://ec.europa.eu/ agriculture/sites/agriculture/files/rural-development-2014-2020/ looking-ahead/rur-dev-small-villages en.pdf (accessed 14/03/2019).

Hosseini S, Frank L, Fridgen G and Heger S (2018) Do not forget about smart towns. Business \& Information Systems Engineering 60(3): 243-257, https://doi.org/10.1007/s12599-018-0536-2.

Ofcom (Office of Communications) (2017) Broadband Coverage and Speeds: Local Statistics. Ofcom, London, UK. See https:// researchbriefings.parliament.uk/ResearchBriefing/Summary/CBP8200\#fullreport (accessed 14/03/2019).

ONS (Office for National Statistics) (2018) Statistical Digest of Rural England. ONS, Newport, UK. See https://www.gov.uk/ government/statistics/statistical-digest-of-rural-england (accessed 14/03/2019).

Ortegon A and Tyler N (2018) The Little Book of City Principles and Practice. ImaginationLancaster, Lancaster, UK.

\section{How can you contribute?}

To discuss this paper, please email up to 500 words to the editor at journals@ice.org.uk. Your contribution will be forwarded to the author(s) for a reply and, if considered appropriate by the editorial board, it will be published as discussion in a future issue of the journal.

Proceedings journals rely entirely on contributions from the civil engineering profession (and allied disciplines). Information about how to submit your paper online is available at www.icevirtuallibrary.com/page/authors, where you will also find detailed author guidelines. 